\title{
The use of cotton grass as oil sorbent in marine environmental protection - preliminary results from experiments
}

\author{
J. Ikävalko ${ }^{1}$, S. Suni ${ }^{2}$, K. Koskinen ${ }^{2}$, A. Aalto ${ }^{1}$, J. Jäänheimo ${ }^{1}$ \\ \& M. Romantschuk ${ }^{2}$ \\ ${ }^{I}$ Department of Biological and Environmental Sciences/Aquatic Sciences, \\ University of Helsinki, Finland \\ ${ }^{2}$ Department of Ecological and Environmental Sciences, \\ University of Helsinki, Finland
}

\begin{abstract}
We have studied the use of cotton grass, a costless side product of peat excavation, as a sorbent of surface oil slicks in a brackish water environment. Two major experiments were run in 2005, where untreated water from the Gulf of Finland (including plankton organisms) was transported into eight large experiment tanks (400 liters each) and diesel oil, cotton grass, oil-degrading bacteria and nutrients, as well as blue (Mytilus spp.) and zebra (Dreissena sp.) mussels were added in different combinations. We studied the effect of diesel oil on phyto- and zooplankton, mussels, and the applicability of the use of cotton grass for eliminating the detrimental effects of oil on test organisms. The applicability of our results are within oil combating: the more we know about which, how, and in what concentrations key species in the Gulf of Finland ecosystem respond to oil, the better we can design and focus oil combating activities to the most ecologically vulnerable areas.

In this paper we will introduce the experiment set-up, measured factors and the first results of our experiments.

Keywords: Baltic Sea, oil, cotton grass, plankton, mussels.
\end{abstract}

\section{Introduction}

Vast volumes of crude and heavy fuel oil are transported in the Baltic Sea, particularly across the Gulf of Finland every year, and activity is projected to 
increase significantly within the next 10 years (Hänninen and Rytkönen [1]). On the average, the vessels used for oil transportation are in an unsatisfactory state, a fact which together with increasing transportation volumes and ice cover in winter increases the risk of an oil spill, and even a large-scale accident (Lonka [2]). Russian oil tankers and wintertime navigation conditions are of particular worry. Due to high shipping activity and its vulnerable and characteristic nature the Gulf of Finland has recently been ranked as one among the Particularly Sensitive Sea Areas (PSSA) by the International Maritime Organization IMO [3].

In case of an oil spill in the Gulf of Finland, several factors will affect the severity of damage to the environment, such as the time of the year (i.e. presence /absence of ice cover), the type and volume of spilled oil, meteorological conditions, oil combating measures taken, the location of the accident (open sea vs. near shore), and the organisms exposed to oil. Principles of these complex interactions are introduced herein. In the Arctic marine environment, important abiotic factors that affect oil spreading and weathering processes include e.g. the presence or absence of ice and snow cover, water temperature, light conditions, and vertical and horizontal water currents (reviewed e.g. by Mackay [4] and Payne et al. [5]). The same factors generally govern the behaviour of oil in the Baltic Sea as well. Biological events in the Baltic ecosystem are strongly linked to specific seasons, thus the possible consequences of a relatively short-lived oil spill depend on the time of the year. Should an oil spill take place during or directly after the ice break-up in spring, it would affect the vernal bloom of ice algae and phytoplankton, and thus the rest of the pelagic food chain. Migratory birds would get disposed to oil, and the oil slick would have a drastic impact on littoral communities as well.

Crude oil and heavy fuel oil consist of hundreds of different aliphatic, branched and aromatic hydrocarbon compounds, the most toxic being the aromatic compounds. The most persistent aromatic hydrocarbons are the polyaromatic hydrocarbons (PAHs), whereas mono-aromates degrade and evaporate faster (Sikkema et al. [6]). Petroleum and its products may have either a mechanical effect, as it is able to penetrate and has a tendency to cling to surfaces forming coverings on objects, or a chemical one, where toxic components (mainly aromatic hydrocarbons of low molecular weight) affect the organism (e.g. Nelson-Smith [7], Wells and Percy [8], Robertson [9]). Organisms can become affected by oil by filtration or ingestion, penetration of oil through cell membranes, or through becoming smothered by oil. Sublethal effects and lethal doses of different oil types on a variety of organisms have been studied extensively, particularly in marine environments (reviewed by, e.g., Malins [10], Engelhardt [11] and Robertson [9]). Such systematic studies of oil effects as those described above are limited from the Baltic region.

An oil sorbent made of cotton grass fibre obtained as a by-product of peat excavation has been shown to function as a very efficient remover of oil from the surface of water (Suni et al. [12]). The sorbent is water repelling, but absorbs oil up to 25 times its own weight. We have designed laboratory experiments to evaluate whether the oil removal capacity of the sorbent is sufficient to eliminate 
the harmful effect of spilled oil in a specific limited volume of water, and whether plankton and/or mussel life can continue in the presence of in situ biodegradation of sorbent bound oil.

Experiments on a) the use of cotton grass fibre as oil sorbent and thus dampening of negative petroleum effects on organisms, b) potential of bacterial oil degradation (biodegradation) within cotton grass on water-oil surface, and c) the effects of diesel on phyto- and zooplankton, and blue and zebra mussels from the Gulf of Finland (eastern Baltic Sea) with and without cotton grass are conducted in closed basins.

\section{Material and methods}

For the first experiment (experiment 1) in June 2005 we transported untreated sea water from the Gulf of Finland into eight experiment basins (320 litres of water into each tank, volume 400 litres each), which were divided into 1) $2 \mathrm{x}$ control, 2) 2x only diesel (400 ml/each), 3) 4x diesel (400 ml/each) and cotton grass fibre sorbent, incubation time either $24 \mathrm{hrs}(2 \mathrm{x})$ or throughout the experiment (28 days, $2 \mathrm{x}$ ).

For the second experiment (experiment 2) in September 2005 water from the same sea area was used, and the experiment basins were divided into 1) $2 x$ control, 2) 2x only diesel (400 ml/each), 3) 2x diesel (400 ml/each) and cotton grass (incubation for $24 \mathrm{hrs}$ ), and 4) $2 \mathrm{x}$ diesel (400 ml/each) and cotton grass (incubation time 28 days). For the study of oil biodegradation in cotton grass 400 $\mathrm{ml}$ of bacterial suspension $\left(10^{7}-10^{8} \mathrm{cfu} / \mathrm{ml}\right.$, grown in $1 \times \mathrm{xM} 9$ medium) and $3,5 \mathrm{~g}$ of $\mathrm{NH}_{4}^{+}$-nitrogen was added to the latter tanks once a week. No carbon or phosphorous was added as $400 \mathrm{ml}$ of diesel was estimated to contain $350 \mathrm{~g} \mathrm{C}$, and the culture medium of bacteria contained $P$ in adequate amounts $(2 \mathrm{~g} / \mathrm{l})$. In the second experiment, 300 individuals of both blue and zebra mussels (total 600 individuals) were collected from the eastern and western Gulf of Finland. 100 mussels were added in each tank (apart the ones with diesel, cotton grass and bacterial addition) and left for the entire duration of the experiment (28 days).

We monitored changes of the following parameters in our experiments:

a) experiment 1: nutrient $(\mathrm{N}, \mathrm{P}, \mathrm{Si}, \mathrm{S})$ and carbon concentrations, water salinity, temperature, $\mathrm{pH}$, hydrocarbon concentrations, concentrations of bacteria, and species composition and abundance of phyto- and zooplankton.

b) experiment 2: nutrient $(\mathrm{N}, \mathrm{P}, \mathrm{Si}, \mathrm{S})$ and carbon concentrations, water salinity, temperature, $\mathrm{pH}$, hydrocarbon concentrations, concentrations of bacteria, species composition and abundance of phyto- and zooplankton, mortality and histopathology of mussels, and rates of oil biodegradation in cotton grass. In this paper, we will introduce some preliminary results of our experiments.

\section{Results and discussion}

Cotton grass proved to be effective in removing oil from the water: after 7 days, the oil concentration of all the basins with cotton grass ( $24 \mathrm{hrs}$ or 28 days incubation) was comparable to that in control basins in experiment 1 (Fig. 1). 
Bacterial densities decreased during the experiment in all basins except the ones receiving only diesel oil (Fig. 2). This suggests that some indigenous bacteria strains in the Gulf of Finland would be capable of using nutrients from diesel and thus degrading it.

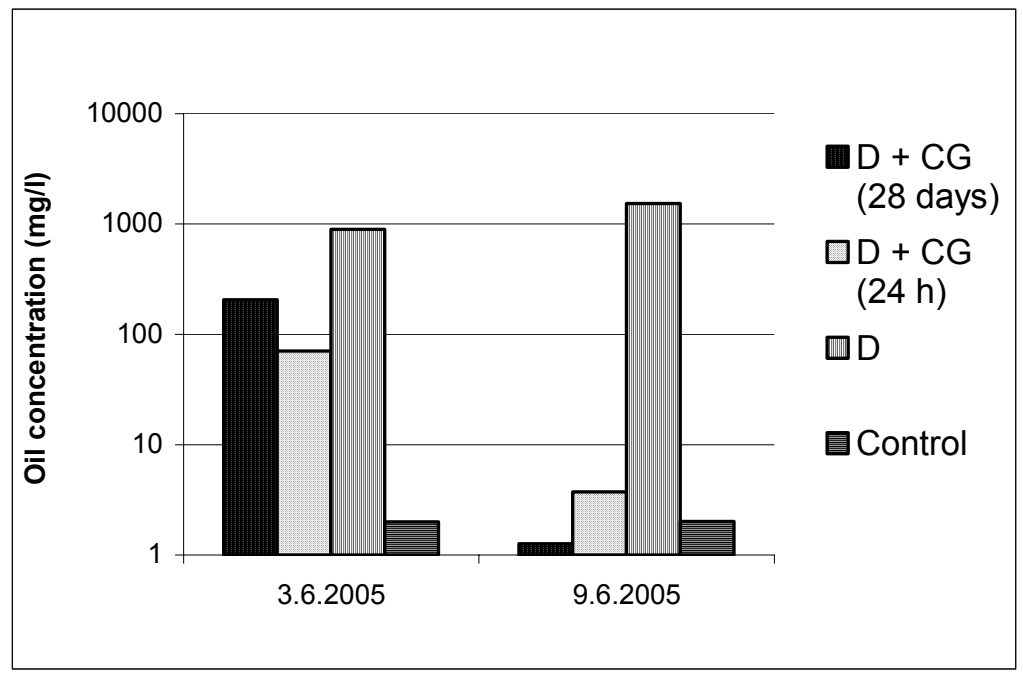

Figure 1: Diesel oil concentration in the experiment $1 . \mathrm{D}=$ diesel only, $\mathrm{D}+\mathrm{CG}(24 \mathrm{~h})=$ diesel + cotton grass (incubation $24 \mathrm{hrs}$ ), D+CG $(28$ days $)=$ diesel + cotton grass (incubation 28 days $)$.

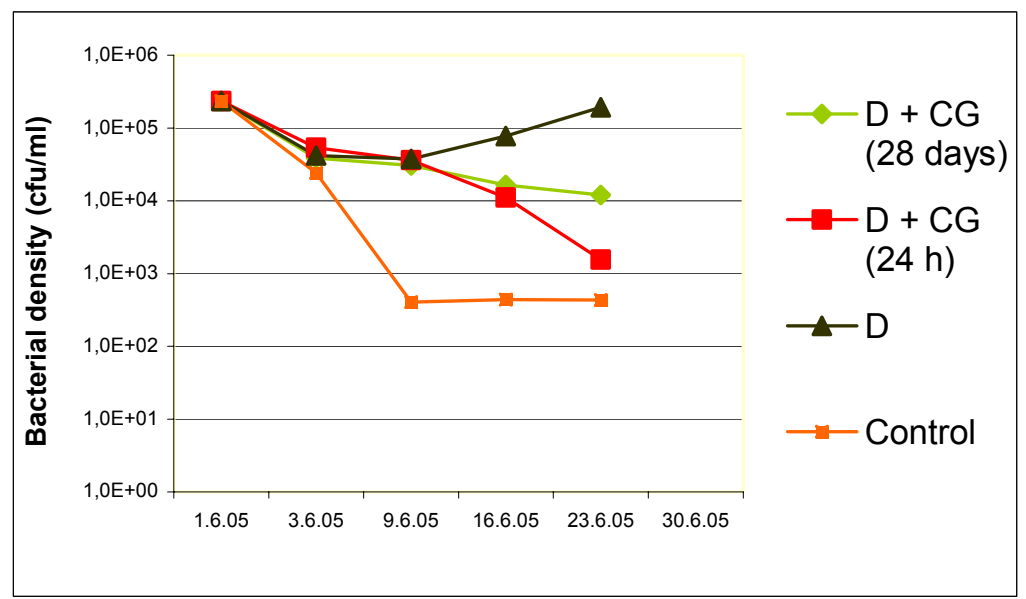

Figure 2: Bacterial density $(\mathrm{cfu} / 100 \mathrm{ml})$ in the experiment $1 . \mathrm{D}=$ diesel only, $\mathrm{D}+\mathrm{CG}(24 \mathrm{~h})=$ diesel + cotton grass (incubation $24 \mathrm{hrs}$ ), D+CG $(28$ days $)=$ diesel + cotton grass (incubation 28 days $)$. 
In the first experiment chlorophyll- $a$ concentration dropped from the initial $9,5 \mu \mathrm{g} / 1$ to almost nil within 16 days in experiment 1 . A temporary increase in chl- $a$ concentration was observed only in control tanks on the second day after diesel addition, after which concentrations dropped dramatically also in controls.

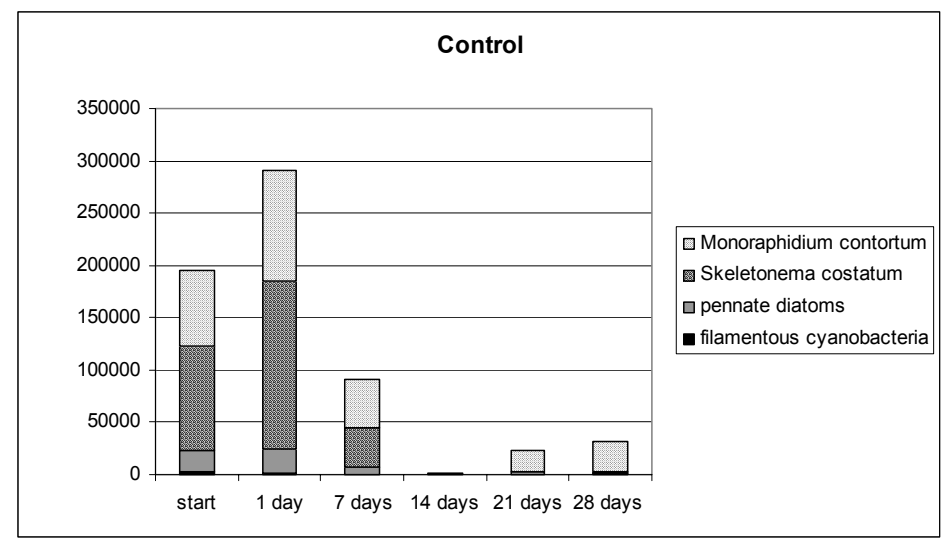

(a)

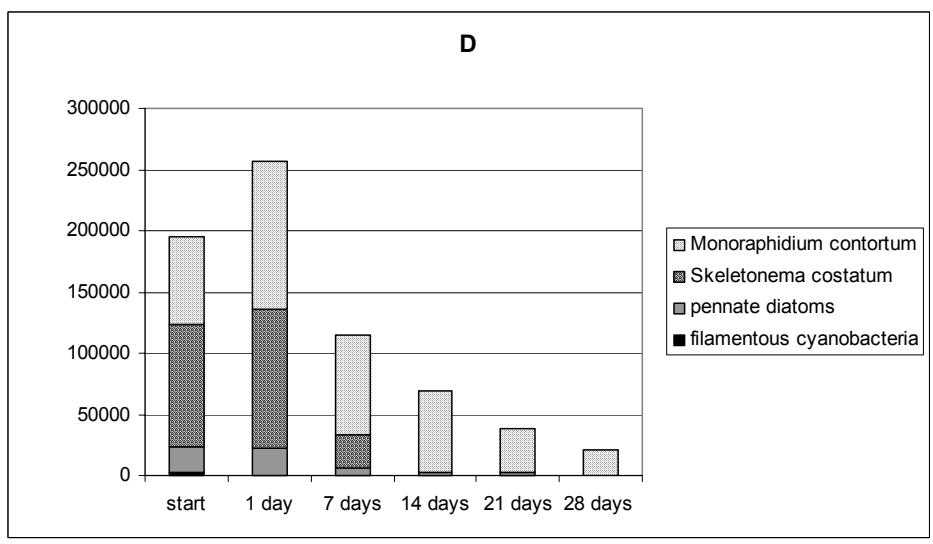

(b)

Figure 3: (a) Microalgae in experiment 1: control tank; (b) Microalgae in experiment 1: tank with diesel only; (c) Microalgae in the experiment 1: tank with diesel and cotton grass (incubation 28 days); (d) Microalgae in the experiment 1: tank with diesel and cotton grass (incubation $24 \mathrm{hrs}$ ). 


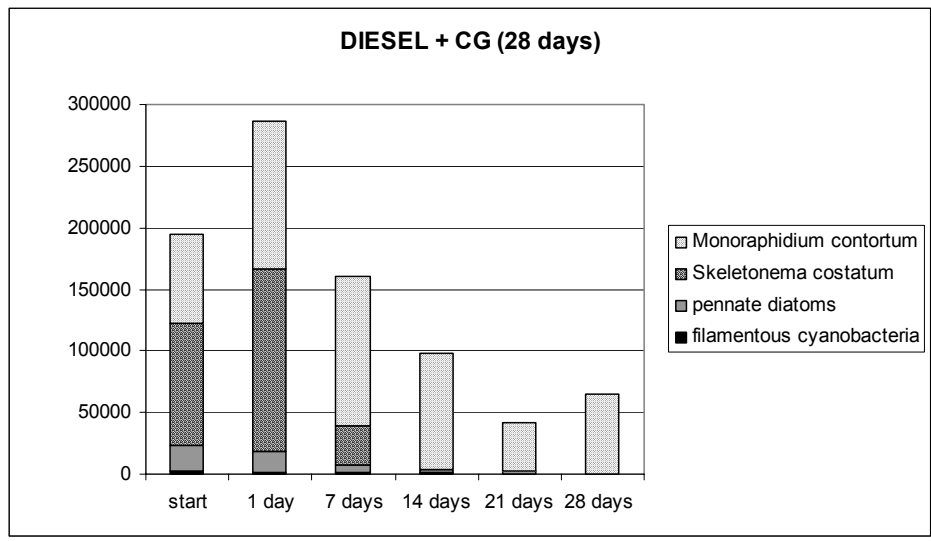

(c)

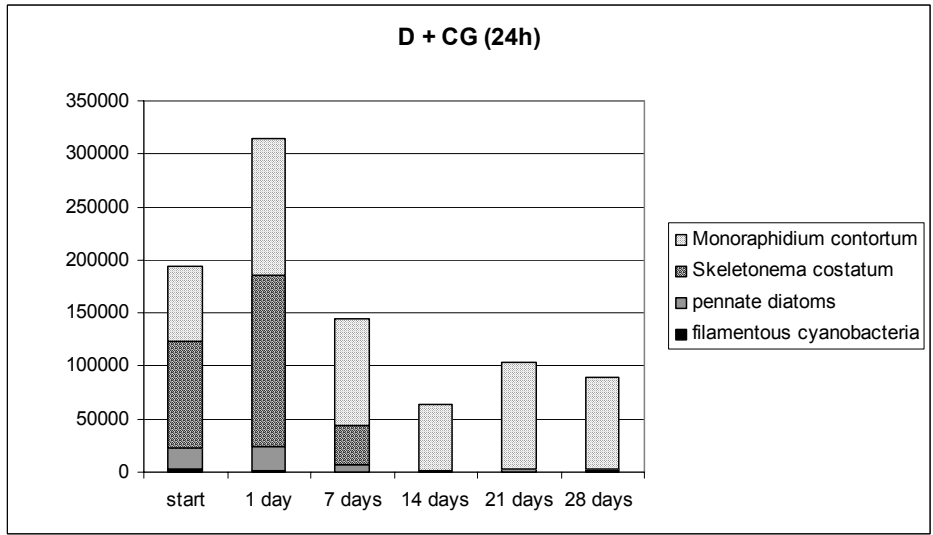

(d)

Figure 3: Continued.

Two species of phytoplankton were clearly dominant at the beginning of experiment 1: the chlorophyte Monoraphidium contortum and the chain-forming diatom Skeletonema costatum. Other abundant taxa throughout the experiment were the filamentous cyanobacteria Achroonema proteiforme and Planktolyngbya limnetica, green algae Scenedesmus, and several pennate diatoms, such as Cylindrotheca closterium as well as the genera Fragilaria and Navicula. Skeletonema costatum and Monoraphidium costatum are good examples of microalgae, which obviously profited first from the excess nutrients brought by the addition of diesel (Figures 3(a)-(d)). However, the toxic effects of diesel - and the possible nutrient limitation in water - lead to a dramatic 
decrease of all phytoplankton algae during later phases of the first experiment. In general, the use of cotton grass dampened the toxic effects of diesel oil on algae but could not remove it completely. Thus, possible causes for the observed decrease of phytoplankton in our experiments are toxic diesel effects, nutrient limitation, and sedimentation of in particular non-flagellated species.

Mussels in experiment 2 indicated that the worst scenario of spilling oil in the sea without combating measures may cause significant mortalities: the addition of only diesel in a tank caused a $100 \%$ mortality of both species. Although the use of cotton grass decreased mortality $(0 \%)$ the animals suffered from histopathological changes, such as inflammatory responses, degenerations and cell death. As it later turned out, the mussels from the western Gulf of Finland were severely contaminated by harmful algae and had thus the best condition in tanks where no diesel oil was added.

\section{References}

[1] Hänninen S. \& Rytkönen J., Oil transportation and terminal development in the Gulf of Finland, VTT Publications 547, pp. 1-151, 2004

[2] Lonka H., Öljy- ja kemikaalivahinkojen torjuntavalmius Suomessa ympäristövahinkojen torjunnan näkökulma, Suomen ympäristökeskus, pp. 1-144 p, 1988 (in Finnish)

[3] IMO, Guidelines for the designation of special areas under Marpol 73/78 and guidelines for the identifiaction and designation of particularly sensitive sea areas, IMO A22/Res. 927, pp. 1-22, 2002

[4] Mackay, D., The physical and chemical fate of spilled oil. Petroleum effects in the Arctic environment, ed. F. R. Engelhardt, Elsevier Applied Science Publishers: Essex, England, pp. 37-61, 1985

[5] Payne, J. R., McNabb, G. D. Jr. \& Clayton, R. Jr., Oil-weathering behaviour in Arctic environments. Polar Res., 10 (2), pp. 631-662, 1991.

[6] Sikkema, J., DeBont, J. A. M. \& Poolman, B. Mechanisms of membrane toxicity of hydrocarbons. Microbiol. Rev., 59, 201-222, 1995.

[7] Nelson-Smith, A. Biological Consequences of oil spills in Arctic waters. The Arctic Ocean. The hydrographic environment and the fate of pollutants, ed. L. Rey, L. (ed.), Macmillan Press Ltd.: London and Basingstoke, pp. 275-293, 1982.

[8] Wells, P. G. \& Percy, J. A. Effects of oil on Arctic invertebrates. Petroleum effects in the Arctic environment, ed. F. R. Engelhardt, F. R. (ed), Elsevier Applied Science Publishers: Essex, England, pp. 101-156, 1985.

[9] Robertson, A. Petroleum hydrocarbons. AMAP Assessment Report: Arctic Pollution Issues. Arctic Monitoring and Assessment programme (AMAP), Oslo, Norway, pp. 661-716, 1988.

[10] Malins, D. C. Effects of petroleum and Arctic and Subarctic marine environments and organisms. Volume II. Biological effects. Academic Press: New York, 500 p, 1977. 
290 Water Pollution VIII: Modelling, Monitoring and Management

[11] Engelhardt, F. R. Petroleum effects in the Arctic environment, Elsevier Applied Science Publishers: Essex, England, 281 p, 1985.

[12] Suni, S., Kosunen, A.-L., Hautala, M., Pasila, A. \& Romanstchuk, M. Use of a by-product of peat excavation, cotton grass fibre, as a sorbent for oilspills. Mar. Pol. Bull. 49, pp. 916-921, 2004. 